\title{
Diabetic neuralgic amyotrophy
}

\author{
Alan J. Williams \\ M.B., M.R.C.P. \\ Department of Medicine, Walsgrave Hospital, Coventry CV2 2DX
}

\begin{abstract}
Summary
A rare neurological condition, neuralgic amyotrophy, in a diabetic is reported. Strong evidence for a causal relationship is suggested. Comment is made on striking similarities between the clinical presentation and course of both diabetic and neuralgic amyotrophy, inferring a similar end pathological process.
\end{abstract}

\section{Introduction}

Neuralgic amyotrophy (acute paralytic brachial neuritis) is a well defined clinical entity (Parsonage and Turner, 1948). Its characteristic presentation is usually intense pain in one or both shoulders followed after a variable interval, from several hours to days, by weakness and later wasting of the affected muscles.

The overall prognosis is excellent, despite the severity and extent of the lesion, and full recovery is to be expected in over $90 \%$ of cases within 3 years.

The aetiology of neuralgic amyotrophy is unknown as it appears that this condition is not confined to any specific disease entity and no particular significance has previously been attached to diabetes mellitus as a possible aetiological factor.

\section{Case report}

A 51-year-old engine fitter, with a 12-year history of diabetes was well controlled on diet and oral hypoglycaemics until the last 2 years, after which control had deteriorated.

In December 1978 the patient first experienced an aching sensation in the front of his thighs and found particular difficulty with climbing stairs and rising from a sitting position.

In August 1979, after losing $7 \mathrm{~kg}$ in weight, treatment with a single daily dose of monotard insulin was commenced, with a return to normoglycaemia.

However, shortly after starting insulin, the patient complained of severe 'stabbing', 'shooting' pains, initially in the left buttock and thigh but shortly becoming bilateral in their distribution. These pains rarely radiated further down his legs, and were predominant at night. During this period the proximal weakness in the patient's legs slowly became more pronounced, but at no time did he complain $\overrightarrow{\overrightarrow{0}}$ dragging of his feet or of problems with micturition.

In early November 1979 the patient became acute aware of a severe ache in his right shoulder and few days later, he started to experience difficulty lifting his right arm above his head.

Direct questioning failed to contribute any mofe to the case history. In particular there was no heredor familial history of similar muscle weakness or wasfing or of diabetes mellitus. Neither was there any history of a recent viral-type illness and the patient had received no inoculations or injections, other than insulin.

On admission to hospital on the 12th Novengb $\vec{\xi}$ 1979, he was afebrile and had no lymphadenop Neurological examination revealed no oculat cranial nerve palsies. Opthalmoscopy revea diabetic retinopathy.

In his upper limbs there was wasting with col siderable weakness of the right deltoid, supra and infra spinati, but no fasciculation was noted. When the patient pushed hard against an immovabie object, marked 'winging' of the right scapula was also seen - a sign that the muscle weakness also involvent serratus anterior (Fig. 1). The tone was assessed normal throughout, and biceps, triceps and supi ator reflexes were symmetrically sluggish bilaterally. No other muscle weakness was noted and there wis no weakness of his left arm. All modalities of sensation were intact.

In the lower limbs both thighs were wasted and 19 fasciculation was observed. There was a mild proximal weakness, asymmetrically distributed, slightly moeㅛ marked on the left than the right. Distal power was strong; the tone was normal; reflexes were absent bilaterally. There was symmetrically diminish sensation to light touch and pin prick below miff thigh bilaterally with absent vibration sense although proprioception sense was intact. Perineal sensation and anal sphincter tone were normal. Co-ordinatien was normal in all limbs. He had no sensory ataxfa and Romberg's sign was negative. His gait was not. mal, but he had considerable difficulty in arising fros the squatting position. Other than finding evidence of postural hypotension with blood pressure 135/ 
$\mathrm{mmHg}$ supine and $90 / 60 \mathrm{mmHg}$ standing, the remainder of the examination was normal.

Investigations were as follows: $\mathrm{Hb} 13.2 \mathrm{~g} / \mathrm{dl}$; WBC $7 \cdot 1 \times 10^{9} / 1$; ESR $28 \mathrm{~mm} / \mathrm{hr}$. Urea and electrolytes normal. Random blood sugar $14 \cdot 1 \mathrm{mmol} / \mathrm{l}$.

$X$-rays: chest, cervical spine, lumbar spine and pelvis normal. Creatinine phosphokinase $32 \mathrm{u} . / \mathrm{l}$. WR negative.

Lumbar puncture pressure normal. Queckenstedt's test normal. Clear colourless fluid. Microscopy: No cells. Protein content raised at $1.23 \mathrm{~g} / \mathrm{l}$, sugar $7 \mathrm{mmol} / \mathrm{l}$.

EMG studies were compatible with a mild mixed mode polyneuropathy. A reduced interference pattern was found in the right shoulder girdle muscles, compared with normal muscle sampling of the left shoulder. No fasciculation potentials were observed.

Ten days after admission the patient developed a similar severe ache in his left shoulder, this was followed after $24 \mathrm{hr}$ by weakness of the same muscles sparing serratus anterior on this occasion.

Within 6 weeks power began returning to both

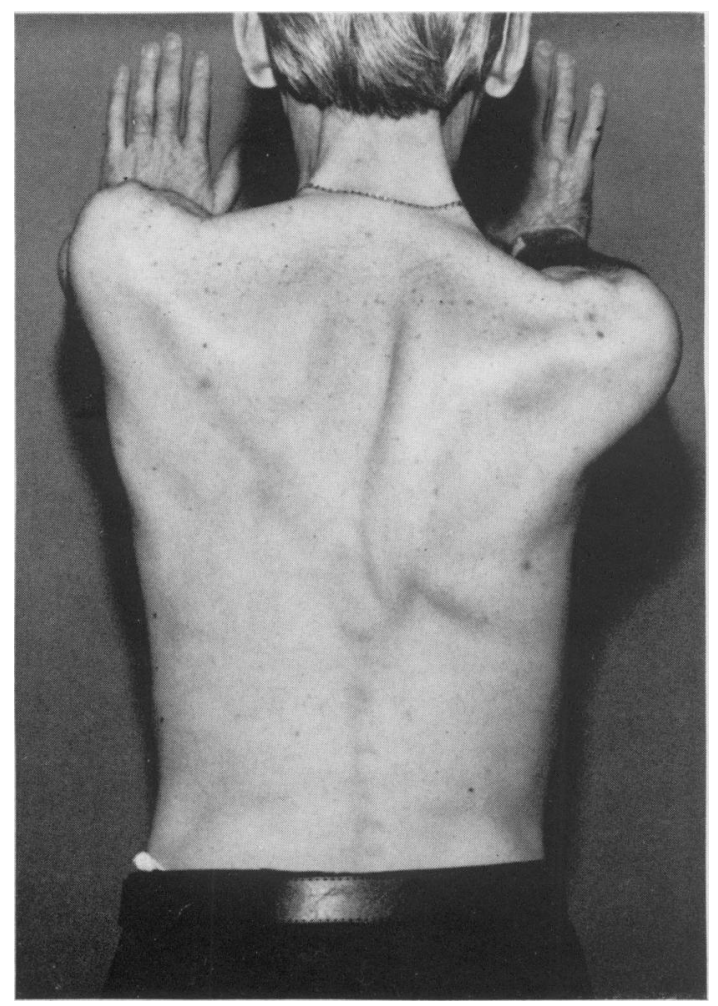

FIG. 1. Dorsum of patient showing 'winging' of right scapula. shoulders and in the past 6 months (mid-1980) this progress has continued.

\section{Discussion}

The co-existence of diabetes and neuralgic amyotrophy cannot be attributed to coincidence.

Firstly, in the above case, the deterioration in diabetic control was followed by the development of many clinical features of diabetic amyotrophy in the lower limbs and subsequently neuralgic amyotrophy in the upper limbs.

Garland originally described the syndrome of diabetic amyotrophy as consisting of 'asymmetrical pain, weakness, muscle-wasting and areflexia in the legs ...' (Garland and Tavener, 1953). He noted the pain was usually severe, sometimes unilateral and of a similar distribution to the amyotrophy. He later observed wasting of small hand muscles and suggested the lesion could occur at any level of the cord (Garland, 1955). This has been confirmed by many authors. The typical amyotrophy involving the upper extremities appears to be a symmetrical bilateral inter-osseous atrophy of the hands rarely involving proximal muscle (Ellenberg, 1968). It is interesting to compare the clinical presentation of the 2 conditions, diabetic amyotrophy and neuralgic amyotrophy. In both, pain usually heralds the onset of muscle weakness and atrophy which usually develop rapidly over the next week. Both tend to have asymmetric limb involvement, and the cerebrospinal fluid protein content may be raised. The prognosis of both is excellent with recovery within a similar time interval (Casey and Harrison, 1972). This leads one to suspect a similar end pathological process, despite the usual occurrence at different levels of the spinal cord. The EMG studies, in the present case, demonstrated the presence of a diffuse neuropathy. This only confirms previous authors' findings in the condition (Weikers and Mattson, 1979) and postulates that the clinical presentation (neuralgic amyotrophy) is only the localized manifestation of a more widespread neuropathy.

Secondly, a few reports on neuralgic amyotrophy have included amongst them cases with diabetes listed as an associated illness (Kennedy and Resch, 1966; Tsairis, Dyck and Mulder, 1972). In some studies these have accounted for up to $14 \%$ of the cases discussed, i.e. more than could be expected from a random sample of the populations involved.

Finally, one suspects that many cases of neuralgic amyotrophy involving diabetics may not have been included in reports as many authors have excluded cases with evidence of a diffuse neuropathy; this is completely unjustifiable as the condition is a clinical entity in its own right. 'Diabetic neuralgic amyotrophy' as an asymmetric form, appears to be compatible with Asbury's suggestion of a clinical 
spectrum of proximal diabetic neuropathy (Asbury, 1977; Raff and Asbury, 1968). A recent article on neuralgic amyotrophy (Editorial, 1980) mentions, amongst the differential diagnoses, diabetic amyotrophy. In view of the above evidence and findings, this warrants re-appraisal as diabetes mellitus appears to play an important aetiological role in some cases of neuralgic amyotrophy.

\section{References}

Asbury, A.K. (1977) Proximal diabetic neuropathy. Annals of Neurology, 2, 179.

CASEY, E.B. \& Harrison, M.J.G. (1972) Diabetic amyotrophy: a follow-up study. British Medical Journal, 1, 656-659.

EDITORIAL (1980) Neuralgic amyotrophy - still a clinical syndrome. Lancet, ii, 729.
EllenbuRG, M. (1968) Diabetic neuropathy of the upper extremities. Journal of the Mount Sinai Hospital, 35, 1 (ब)

GaRLAND, H. (1955) Diabetic amyotrophy. British Mediral Journal, 2, 1287.

GARLAND, H. \& TAVERnER, D. (1953) Diabetic myelopat British Medical Journal, 1, 1405.

Kennedy, W.R. \& ReSCH, J.A. (1966) Paralytic braç neuritis. Journal Lancet. Minneapolis, 86, 459.

Parsonage, M.J. \& Turner, J.W.A. (1948) Neuralgic amȳtrophy: the shoulder-girdle syndrome. Lancet, i, 973.

RAFF, M.C. \& ASBURY, A.K. (1968) Ischemic mononeuropathy and mononeuropathy multiplex in diabeles mellitus. New England Journal of Medicine, 279, 17.

Tsairis, P., Dyck, P.J. \& Mulder, D.W. (1972) Natural history of brachial plexus neuropathy. Archives $\rightarrow$ f Neurology, 27, 109.

Weikers, N.J. \& Mattson, R.H. (1979) Acute paralyळic brachial neuritis. Neurology. Minneapolis, 19, 1153. 